\title{
A FILOSOFIA DA CIÊNCIA: MATERIALISMO RACIONAL E FORMAÇÃO DO ESPÍRITO CIENTÍFICO NA VISÃO DE BACHELARD ${ }^{1}$
}

\section{The philosophy of science: rational materialism and formation of the scientific spirit in the vision of Bachelard}

Eleno Marques de Araújo - UNIFIMES/Brasil Emerson Mateus Souza Duarte - UNIFIMES/Brasil

RESUMO: O presente trabalho é resultado de uma análise minuciosa nas obras-primas de Gaston Bachelard no que tange a filosofia das ciências: A Formação do Espírito Científico, A Epistemologia e O Materialismo Racional. Buscamos constatar o parecer filosófico bachelardiano sobre o conhecimento empírico (senso comum) e o conhecimento científico e filosófico, como formas de descobertas de métodos científicos que auxiliaram no desenvolvimento das ciências exatas e evolução do mundo moderno, além das análises de diversas experiências realizadas no decorrer da evolução do cientista, suas criações e seus resultados, assim como as metodologias utilizadas para chegar às suas conclusões. Constatamos que um filósofo não deve limitar suas informações a generalizações ingênuas. Frente aos primeiros obstáculos é necessária uma busca incansável por novidades. Sair da inércia e não se contentar com resultados de realizações imediatas. O cientista deve sempre desejar novos conhecimentos e buscar continuamente o saber, ter o domínio total da metodologia e dos instrumentos a serem utilizados nas experiências que resultarão no avanço da ciência. Nunca dar-se por vencido pelo cansaço, pela frustação ou pelos fracassos que lhe serão sobrepostos, pois para chegar a resultados novos é necessário fazer o que ninguém fez ainda.

Palavras-chave: Conhecimento. Metodologia. Informação.

\begin{abstract}
The present work is the result of a detailed analysis of Gaston Bachelard's masterpieces in the philosophy of science: The Formation of the Scientific Spirit, Epistemology and Rational Materialism. We sought to verify the Bachelardian philosophical opinion on empirical knowledge (common sense) and scientific and philosophical knowledge, as ways of discovering scientific methods that aided in the development of the exact sciences and evolution of the modern world, in addition to the analysis of various experiences during the course the evolution of the scientist, his creations and his results, as well as the methodologies used to arrive at his conclusions. We find that a philosopher should not limit his information to naive generalizations. In front of the first obstacles is a relentless search for news. Get out of inertia and not be content with results of immediate accomplishments. The scientist must always desire new knowledge and continually seek knowledge, have full control of the methodology and instruments to be used in the experiments that will result in the advancement of science. Never give up on tiredness, frustration, or failures that will overlap you, for to achieve new results it is necessary to do what no one has done yet.
\end{abstract}

Keywords: Knowledge. Methodology. Information.

Educação, Psicologia e Interfaces, Volume 4, Número 1, p. 215-216, Janeiro/Março, 2020.

ISSN: 2594-5343. DOI: https://doi.org/10.37444/issn-2594-5343.v4i1.166 


\section{INTRODUÇÃO}

O conhecimento que possuímos atualmente é resultado de um longo processo de aprendizado que foi acumulado ao longo da evolução humana. Também é fruto de inúmeras pesquisas realizadas incansavelmente por pessoas que afim de chegar ao fundo do saber supremo esmeraram em busca de novos saberes. O homem sempre esteve disposto a desbravar e conquistar o mundo, e quando o fez, sentiu necessidade de viajar pelo espaço, até que tudo fosse conhecido por ele. O materialismo, a vontade de ter e de poder, é o que o motiva a querer saber cada vez mais, e quanto mais sabe, mais deseja conhecer.

A escrita, as ondas de rádio, a eletricidade, a internet, medicamentos, etc., "tudo" o que existe nos dias atuais, existe graças às buscas e experiências realizadas ao longo da história da humanidade, indo desde um passado remoto até os dias atuais. As buscas humanas pelo conhecimento tem por finalidade tornar o mundo um lugar melhor e mais seguro para todos.

No início, as descobertas aconteciam naturalmente, sem a iniciativa ou interesse do homem em obtê-las, como no caso do fogo, que, como sabemos passou a ser usado e reproduzido pelo homem, graças a raios que caíam sobre as florestas e geravam a combustão espontânea ou das erupções vulcânicas que encandeciam em sua volta. $\mathrm{O}$ homem aproveitando desta dádiva da natureza, se mantinha próximo, para se aquecerem e manterem afastados seus predadores. Logo ele viu que aquilo era bom, e que seria necessário aprender a produzi-lo, e não ficar refém da natureza, à espera do milagroso fecho de luz que caíra dos céus ou emergisse das profundezas da terra. Descobriu que ao gerar atrito entre duas rochas surge uma faísca, que consequentemente, dá início ao fogo se exposto ao oxigênio e entrar em contato com algum combustível (lenha, folhas, etc.).

Logo em seguida ele sentiu necessidade em desenvolver métodos para se comunicar com os demais, a fim de se agruparem e se manterem protegidos, visando a sobrevivência do grupo (ARISTÓTELES, 1999). E assim fora evoluindo pouco a pouco conforme o conhecimento que ia obtendo. De lá para cá, o homem entrou numa busca implacável pelo saber, que mudaria os rumos da história da humanidade. Entretanto,

Educação, Psicologia e Interfaces, Volume 4, Número 1, p. 205-216, Janeiro/Março, 2020.

ISSN: 2594-5343. DOI: https://doi.org/10.37444/issn-2594-5343.v4i1.166 
A filosofia da ciência: materialismo racional e formação do espírito científico na visão de Bachelard

várias teorias foram criadas a fim de expor os conhecimentos obtidos, algumas contestadas e falseadas, outras perduram através do tempo.

A transição da Era Antiga para a Contemporânea foi marcada pelas emoções imediatas e realizações mais simples, para não dizer medíocres, advindas de experimentos primitivos, que fechavam a mente do cientista para descobertas maiores. Entretanto, os resultados anteriores possibilitaram que futuramente outros investigadores fossem responsável por novas descobertas e concluíssem ciclos investigativos a respeito de determinada matéria, isto é, de novas teorias.

Como se tratava de um período de muitas descobertas, era comum surgir vários indivíduos se intitulando cientistas e propondo diversas teorias. Como não se tinha conhecimento sobre determinadas áreas, muitas dessas descobertas acabavam por se tornarem vazias, baseadas em pensamentos evidentes, provenientes de realizações primitivas e embasadas no conhecimento vulgar e caiam no esquecimento. Entretanto, com o passar dos anos, e o alavancar de novas metodologias de pesquisa, com a formação do espírito científico, outras teorias foram derrubadas, quebrando os velhos conceitos e implementando no mundo científico, a verdade erudita.

Por ser uma pesquisa de revisão bibliográfica, os materiais utilizados para composição deste artigo, foram as obras-primas do famoso escritor francês Gaston Bachelard (A Epistemologia, A Formação do Espírito Científicos e O Materialismo Racional), além de artigos científicos, teses e dissertações.

A metodologia utilizada foi de leituras e fichamentos das obras supracitadas, com a finalidade de formar um banco de dados que oportunizasse a composição do texto a partir do pensamento de Bachelard sempre voltados para o ramo da filosofia das ciências, da poesia e do conhecimento científico.

\section{RUPTURA COM O CONHECIMENTO COMUM}

No percurso de produção científica, quando nos deparamos com um fenômeno que, a princípio, nos oferece um certo grau de dificuldade para ser resolvido, a primeira sensação do filósofo das ciências é constatar a dificuldade apresentada, como é descrito no trecho abaixo:

Educação, Psicologia e Interfaces, Volume 4, Número 1, p. 215-216, Janeiro/Março, 2020.

ISSN: 2594-5343. DOI: https://doi.org/10.37444/issn-2594-5343.v4i1.166 
Porque a nossa captação imediata do real não atua se não como um dado confuso, provisório, convencional, e esta captação fenomenológica exige inventário e classificação. Por outro lado, é a reflexão que dará um sentido ao fenômeno inicial, sugerindo sequência orgânica de pesquisas, numa perspectiva racional de experiências. Não podemos ter a priori nenhuma confiança na informação que o dado imediato pretende fornecer-nos (BACHELARD, 1971, p. 17).

Anteriormente não se detinha conhecimento dos componentes a serem utilizados nas experiências científicas, quais suas funções e sua origem, portanto, as experimentações se tornavam cruas e superficiais, incapazes de chegarem aos objetivos desejados. Doravante o conhecimento acumulado sobre as experimentações anteriores, acabaram por ser um grande passo no caminho do descobrimento científico, uma vez que os cientistas foram encontrando seus próprios caminhos através das experimentações. Neste sentido, o surgimento de instrumentos de pesagem, a medição dos elementos, o isolamento de componentes da pesquisa foram também, de suma importância para o desenvolvimento das ciências exatas como a química, a física e a matemática. Posteriormente, já no mundo contemporâneo, percebe-se uma ruptura do conhecimento vulgar, comum, migrando para um conhecimento epistemológico, filosófico e científico por excelência.

Evocamos aqui uma analogia simples para exemplificar a produção científica daquela do senso comum. Como fazer um bolo, sem saber quais os ingredientes a serem usados na receita? Qual a quantidade de cada um deles? Este exemplo pode ser aplicado aos experimentos feitos em qualquer laboratório. Devido aos métodos primitivos e a falta de instrumentos adequados que permitissem o uso de itens exatos, não era possível obter resultados concisos e eficazes nos experimentos realizados. Com o passar do tempo e o surgimento de novas tecnologias, foi possível aprimorar as metodologias científicas, obter exatidão nos dados e fatores que levariam aos resultados esperados.

Segundo a visão de Bachelard, a experiência no ponto de vista dos empiristas é uniforme em sua essência, pois tudo advém da sensação, por meio dos órgãos dos sentidos: tato, paladar, olfato, visão e audição. Já para os idealistas é uniforme porque é impermeável à razão. Se assim for, aí está o dever do filósofo, não se limitar às informações dadas à primeira vista, mas ter a "fome" de conhecimento, indagar a todo momento sobre os fatos obtidos e ir em busca de possibilidades e de novos saberes. Traçando este caminho, a ciência e a filosofia falavam a mesma linguagem, pois ambas 
A filosofia da ciência: materialismo racional e formação do espírito científico na visão de Bachelard

advêm da experiência tais como: pesagens, medidas, qualidades, quantidades etc. Neste interim, os dados são concisos o que limita a possibilidade de novos fenômenos e consequentemente a ampliação do conhecimento. Porém, a atitude do filósofo deve ser a de sempre desconfiar e gerar dúvidas sobre as experiências já desenvolvidas. Dessa forma, o saber está sempre em evidência, e nunca ficaria blindado, como que já tivesse atingido seu limite de verdade e não mais avançaria. O conhecimento avança com novas proposituras que questionam as verdade postas, nossos experimentos são realizados e o fenômeno é sempre novo aos olhos do cientista.

\section{DEVER DO EPISTEMÓLOGO}

A epistemologia nada mais é do que um ramo da filosofia que se objetiva em estudar a origem do conhecimento, tendo como base o racionalismo, a fim de determinar e provar seus conceitos e valores ali depositados. O epistemólogo, é, portanto, um investigador dedicado e determinado, que busca resolver todos os obstáculos epistemológicos que lhe são postos, inerentes ao seu objeto em questão. É ele que faz a análise minuciosa de tudo aquilo que se pode crer, indo das causas e fundamentos do conhecimento até às questões de sua relação com a verdade erudita e sobre as crenças que nela são depositadas, até investigar e justificar todos os critérios a fim de afirma-los e consolida-los em forma de conhecimento. Entretanto, existem algumas condições para o conhecimento avançar, assim como existem certos empecilhos, que vão dificultar o seu avanço:

Quando se procuram as condições psicológicas do progresso, e não se trata de considerar obstáculos externos, causas de estagnação e até de regressão, detectaremos causas de inércia, as quais daremos o nome de obstáculos epistemológicos (BACHELARD, 1953, p. 17).

Conforme a afirmação bachelardiana acima os obstáculos epistemológicos são os entraves que a ciência, ou melhor, que o cientista encontra para avançar no aprofundamento de suas investigações, ou seja, o retrocesso, a inércia dentre outros.

\section{O MATERIALISMO RACIONAL}

Educação, Psicologia e Interfaces, Volume 4, Número 1, p. 215-216, Janeiro/Março, 2020.

ISSN: 2594-5343. DOI: https://doi.org/10.37444/issn-2594-5343.v4i1.166 
O percurso de produção científica de um filósofo da ciência pode ser carregado de muitos obstáculos, dentre eles destacam-se a preguiça e a negligencia. O pesquisador deve estar sempre atento para supera-los e devanear ao presenciar algo inédito, deve suprir toda e qualquer desmotivação advindas dos insucessos e fracassos que lhe ocorrem em função da experiência nesta trajetória da pesquisa, sempre buscando algo de novo e mantendo a verdade por princípio.

Toda e qualquer investigação científica tem sempre um ponto inicial de onde as pessoas imbricadas na investigação partem como pressupostos hipotéticos na busca dos resultados que confirmem ou não tais hipóteses. Neste sentido, Bachelard (1996, p. 25) assegura que:

A primeira experiência, ou, para ser mais exato, a observação primeira, é sempre um obstáculo inicial para a cultura cientifica. De fato, essa observação primeira se apresenta repleta de imagens; é pitoresca, concreta, natural, fácil. Basta descrevê-la para se ficar encantado.

Bachelard sustenta que a primeira observação do fenômeno a ser investigado é a que deve encantar o cientista, por que as experiências que apresentavam resultados falhos, em um segundo teste ou segunda observação, já não eram tão falhos quanto aparentavam. Em muitos casos foram das repetições dos experimentos, que viriam novas ideias para chegar ao sucesso e possibilitar novas descobertas.

Todos os pesquisadores, mas sobretudo os natos, devem a princípio, ignorar toda e qualquer imagem que lhe possa associar ao seu objeto de experiência e que lhe prenda a atenção e o torne inerte. Muitas vezes as coisas, entes ou objetos, não são como aparentam ser. Neste interim, é dever do cientista, romper com as barreiras que lhes são impostas e não ficar estagnado, preso a apenas um conceito ou uma perspectiva relacionada aquele assunto em investigação. Certamente fracassos e insucessos vão ocorrer em quase todas as experimentações, é, portanto, de sua responsabilidade aprender com os próprios erros, olhar o objeto não como um todo, mas examinar isoladamente os pormenores dos detalhes, sempre descartando as primeiras impressões.

Não confiar no abstrato tem sido a regra primordial no meio científico. Entretanto, estudar para compreender, chegar aos fatos, indo dos princípios gerais, percorrendo o caminho do descobrimento real e concreto até atingir os princípios específicos, revela ser o caminho correto para novas informações e o avanço da ciência e tecnologia. Neste 
A filosofia da ciência: materialismo racional e formação do espírito científico na visão de Bachelard

ínterim, o cientista deve interrogar-se constantemente a cada dado obtido como resultado de suas inquirições.

Um caminho a ser seguido necessariamente por qualquer filósofo da ciência terá que ser o de pesquisar a filosofia dos objetos, afim de chegar ao verdadeiro conhecimento de como eles são apresentados fenomenicamente, como ser aí no mundo. Dar relevância ao infinitamente pequeno, e, que quase sempre passa despercebido aos olhos comuns, mas que jamais poderá furtar a percepção do filósofo, analisar e se questionar a todo instante, gerando e respondendo as próprias dúvidas que a cada resultado das experimentações vão surgindo.

A obtenção e o acúmulo do conhecimento fez com que o homem tivesse novas necessidades, daí que quanto mais ele apreende, mais o quer apreender, não saciando com o saber já conquistado, está sempre buscando novidades, é o que faz a roda do conhecimento girar, e o mundo evoluir.

Para o pesquisador, quanto mais difícil for o problema, maior deve ser a vontade de resolvê-lo. Muitas vezes, o insucesso em suas experiências, é que o motiva cada vez mais para resolvê-las. Concluir uma experiência tida como utópica, provar o que ainda não foi provado, destruir as barreias do impossível é o objetivo de todo pesquisador. Tornar pública a filosofia sobre determinado assunto, objeto e/ou experiência que não se tinha conhecimento, ou se já o tinha, porém superficialmente, deve agora, no âmbito da filosofia da ciência, esclarecer todas as dúvidas, chegando a um resultado exato, conciso, com dados específicos. Traçar uma fronteira e ultrapassá-la será o seu maior triunfo, pois para construir um mundo novo, é preciso que o anterior seja destruído, contestar velhas ideias e conceitos antigos, já o empreendeu Descartes com O Discurso do Método.

Para examinar psicologicamente o materialismo cientifico, é necessário vê-lo com diferentes perspectivas, pois ele nos aparecerá como uma estrutura imóvel que necessita ser rompida da inércia. É preciso insistência no insucesso para não ficar preso num materialismo cansado e falho, ter a insatisfação a cada resultado obtido para chegar ao verdadeiro materialismo científico, pois ele é a ciência do futuro, que visa produzir descobertas e retificar a ideia científica nos próximos séculos.

Por outro lado, o racionalismo propõe ao cientista, explicações óbvias e que sejam claramente vinculadas à razão, sempre se questionado e respondendo às perguntas de 
modo rápido e objetivo, a fim de que não sejam geradas novas questões sobre o proposto, enraíza-se, portanto, no senso comum, em teorias já verificadas, experimentos já realizados, e presos em uma metodologia tradicional. Neste sentido, o investigador deve realizar sempre uma boa avaliação sobre a experimentação em questão, isto é necessário, uma vez que uma análise bem-feita dos elementos a serem utilizados trará ao cientista maior precisão e consequentemente reduzirá as chances de fracasso, o conhecimento e total domínio da metodologia utilizada na pesquisa garantirá o sucesso da investigação.

Dessa maneira, o pesquisador deve adotar uma metodologia de observação do objeto, não como um todo, como ele é apresentado e manifestado no mundo, mas sim isolando-o sob todos os pontos de vista, visando sempre manter uma perspectiva divergente da banal, abandonando velhos preceitos, pois isolando um ente qualquer que seja, por exemplo um corpúsculo, ele poderá se tornar um centro de irradiação para um fenômeno maior e integrado no mundo e dessa forma a pesquisa será bem sucedida.

\section{A FORMAÇÃO DO ESPÍRITO CIENTÍFICO}

Uma pergunta norteadora inicialmente, embora elementar, mas que certamente muitas pessoas nunca se detivera a ela pode ser: já pensaram quantos fracassos em experiências científicas ocorreram para chegar ao conhecimento e às novas descobertas? Se analisarmos o campo da saúde, talvez seja surpreendente a quantidade de pessoas enfermas que morreram, simplesmente por ter sido dado a ela uma quantidade inexata de um remédio. O excesso da dosagem, ou ausência de determinado medicamento no organismo pode causar sérios riscos à saúde, ou até mesmo, levar o indivíduo ao óbito. Seguindo a mesma linha de raciocínio, ainda na medicina, foram inúmeras perdas de vidas, se pensarmos em quantas pessoas que foram tidas como cobaias de experiências primeiras, no ramo das ciências médicas, quantas "cirurgias" foram feitas sem que se tivesse o conhecimento da anatomia humana, levando consequentemente ao óbito. Quantas vezes que por um simples detalhe, um corte de uma artéria ao invés de uma veio comum, a retirada de parte de algum órgão vital para nossa sobrevivência, quantos sacrifícios não foram feitos, para que se descobrisse a cura ou tratamento de algum tipo de enfermidade.

Boa parte do conhecimento que se tem hoje foi passada de geração em geração, de pai para filho e assim por diante, remédios caseiros, normas de moral, ética e jurídicas,

Educação, Psicologia e Interfaces, Volume 4, Número 1, p. 205-216, Janeiro/Março, 2020.

ISSN: 2594-5343. DOI: https://doi.org/10.37444/issn-2594-5343.v4i1.166 
A filosofia da ciência: materialismo racional e formação do espírito científico na visão de Bachelard

a escrita e muito mais. É com esse mesmo comprometimento que se funda a verdadeira filosofia. Ela investiga os fatos, independente dos fracassos, das perdas. O filósofo das ciências deve se manter firme e focado, concentrado no seu objetivo que almeja provar. Cada experiência deve abrir um portal para um mundo novo, com novas expectativas e uma diferente visão do objeto, para que não cometa o mesmo erro novamente, mas apreender também dos erros para não cometê-los novamente.

O filósofo das ciências deve adaptar-se às características das novas ciências, encontrar-se atualizado com a tecnologia, aprender a implementar e desenvolver novas metodologias de investigação, haja vista que nem sempre a técnica utilizada é compatível com o objeto pesquisado. $\mathrm{O}$ insucesso de sua experiência pode estar ligado não a dificuldade da proposta em si, mas a um método de resolução deficitário, ou incapaz de obter o resultado esperado. Se pesquisador não for capaz de solucionar os problemas, logo, não deve descartar a investigação, mas procurar por outras vias a solução da problemática investigada. O processo de investigação não deve ser carregado por excesso de expectativa na obtenção de resultados imediatos, pois como dito anteriormente, o que é tido à primeira vista, nem sempre é o que se espera e pode confundi-lo, levando-o ao conhecimento comum e não ao científico.

O pesquisador é movido por seus objetivos e pensamentos, suas ações são tomadas mediante ao conhecimento que possui. Neste sentido, a humanidade dispende boa parte de sua existência na busca do saber, e quanto mais o alcança, mais constata que necessita buscá-lo.

As descobertas científicas feitas até hoje, foram através de experiências, muitas delas com os primeiros resultados fracassados, mas os pesquisadores não desistiram e repetiram os experimentos até conseguir êxito. Qual o valor de uma experiência bemsucedida? A experiência deve esclarecer todas as dúvidas e incógnitas pertinentes a ela, precisa alcançar todas as expectativas depositadas nela e se nela conter um vício, ou falha, seja de planejamento ou execução, a mesma deve ser descartada, caso contrário, se cumprir os requisitos mencionados anteriormente, pode-se considera-la bem-sucedida. $\mathrm{O}$ valor dessa experiência, é, portanto, descobrir o caminho a ser trilhado para chegar a um determinado resultado, é como se fosse um manual de instrução.

\section{CONSIDERAÇÕES FINAIS}

Educação, Psicologia e Interfaces, Volume 4, Número 1, p. 215-216, Janeiro/Março, 2020.

ISSN: 2594-5343. DOI: https://doi.org/10.37444/issn-2594-5343.v4i1.166 
A partir das afirmações acima, conclui-se que os estudos realizados por Bachelard, foram de suma importância para a renovação e evolução das ciências, sejam elas exatas, humanas, etc., porém, ambas no campo da filosofia das ciências. As diversas experiências mencionadas e estudadas minuciosamente realizados pelo pesquisador francês em suas obras, reafirmam a necessidade de rompimento do conhecimento comum e a necessidade do filósofo dedicar-se as análises do pensamento científico.

Boa parte da história da humanidade foi marcada por decepcionantes experiências, teses mal formuladas e mal embasadas. Porém não por culpa ou descaso do cientista, mas porque em muitos casos o pesquisador não dispunha das condições básicas e nem de tecnologias adequadas que fossem capazes de garantir o resultado esperado para sua teorias.

O senso comum guiou por muito tempo, e ainda guia, diversos caminhos de nossas vidas, muitas vezes acreditamos apenas nas aparências e no conhecimento vulgar que possuímos sobre determinadas áreas do saber humano. Deixamos a preguiça e a inércia nos guiar, com uma perspectiva muito rasa e infértil na busca do conhecimento. Portanto, perdemos a graça e o desejo na busca da verdade e do significado do objeto investigado.

As obras de Bachelard, no que tange a filosofia das ciência, são de enorme incentivo a formação e construção de pensamento científico, não se limita apenas a experiências das áreas de ciências exatas, mas ajuda o pensador amador a fundar seu alicerce e estruturar sua filosofia, enquanto cientista. Abre a mente do leitor para um mundo repleto de perspectivas e rompimento de diversas ideias, introduz nele uma forma epistêmica de olhar as coisas no mundo como elas realmente são.

Conclui, que para o avanço das investigações de um filósofo da ciência, o mesmo nunca deverá se abster nos dados de experiências primárias, deve ter um olhar panorâmico de tudo que se passa ao seu redor e ao redor do mundo. Jamais ficar preso a um materialismo empírico, que se manifesta fenomenicamente de imediato, satisfeito com suas primeiras experiências e resultados, presos em preceitos vagos e míticos. Não deve manter-se estagnado ou até mesmo regredir por conta dos obstáculos epistemológico. É necessário destruir toda e qualquer opinião já formada sobre determinado assunto, pois, ela é o primeiro obstáculo na vida do pesquisador, é, portanto, trilhar por um materialismo erudito, científico, filosófico, instruído pela repleta pluralidade dos diversos conhecimentos existentes e ir em busca de novas descobertas. Sempre propondo novas

Educação, Psicologia e Interfaces, Volume 4, Número 1, p. 205-216, Janeiro/Março, 2020.

ISSN: 2594-5343. DOI: https://doi.org/10.37444/issn-2594-5343.v4i1.166 
A filosofia da ciência: materialismo racional e formação do espírito científico na visão de Bachelard

indagações e as respondendo de forma correta e instruída, pois só haverá respostas se houverem perguntas, que estão sempre a se manifestar, porém, quase sempre não são percebidas.

A proposta de Bachelard, além de citar minuciosamente algumas das mais importantes experiências do ramo científico e seus criadores, citando, algumas obras também filosóficas com a finalidade de comprovar as teses afirmadas pelos diversos filósofos e cientistas. O percurso da investigação vai do surgimento de determinada teoria, passando pelos fracassos das primeiras experimentações até atingir o sucesso com os resultados demonstrados. Apresenta também o objetivo de estimular e motivar constantemente o leitor, a trilhar os mesmos caminhos dos pesquisadores primeiros, desfrutando das diversas tecnologias e instrumentos modernos que obtemos atualmente, a fim de otimizar o tempo entre o experimento e o resultado, reduzindo as chances de insucesso das experiências.

\section{Notas de rodapé}

${ }^{1}$ Este artigo é resultado de pesquisa PIBIC/UNIFIMES 2018.

\section{REFERÊNCIAS BIBLIOGRÁFICAS}

BACHELARD, Gaston. A Epistemologia. Tradução de Fátima Lourenço Godinho e Mário Carmino Oliveira. Lisboa: Edições 70, 1971.

BACHELARD, Gaston. A Formação do Espírito Científico: contribuições para uma psicanálise do conhecimento. Tradução de Estela dos Santos Abreu. Rio de Janeiro: Contraponto, 1996.

BACHELARD, Gaston. O Materialismo Racional. Tradução de João da Gama Lisboa: Edições 70, 1953.

CARVALHO, Marcelo de. Gaston Bachelard e a Renovação da Episteme no Século XX. Ensaios Filosóficos, Volume 1. Outubro/2010. p. 103-125. Disponivel em: <http://www.ensaiosfilosoficos.com.br/Artigos/Artigo2/Ensaios_Filosoficos_Volume_I I.pdf $>$. Acesso em: $<10 / 10 / 2018>$.

LOPES, Alice Ribeiro Casimiro. Bachelard: o Filósofo da Desilusão. Cad. Cat. Ens. Fis., v.13, n. 3: p. 248-273, dez. 1996.

RODRIGUES, Horácio Wanderlei; GRUBBA, Leilane Serratine. Bachelard e os obstáculos epistemológicos à pesquisa científica do direito. Sequência. n . 
64. Florianópolis, 2012. Disponível em: <http://dx.doi.org/10.5007/21777055.2012v33n64p307>. Acesso em: <30/08/2018>.

VELANES, David. Alguns Aspectos Sobre o Novo Espírito Científico na Epistemologia de Gaston Bachelard. SABERES, Natal RN, v. 1, n. 16, Agosto, 2017, 66-82.

\section{Credenciais dos autores}

ARAÚJO, Eleno Marques de. Doutorado em Ciências da Religião pela Universidade Católica de Goiás, Brasil (2012). Adjunto do Centro Universitário de Mineiros, Goiás. Pós doutorado pela UNIUBE - Universidade de Uberaba, no Programa de Pós-Graduação em Educação, sobre a orientação da Profa. Dra. Vânia Maria de Oliveira Vieira. Professor no Centro Universitário de Mineiros-Unifimes. E-mail: profelenoaraujo@ outlook.com

DUARTE, Emerson Mateus Souza. Acadêmico do $4^{\circ}$ período de Direito no Centro Universitário de Mineiros, Unifimes. Email: emersonmateus.emsd@gmail.com

Endereço para correspondência: Eleno Marques de Araújo. Centro Universitário de Mineiros, R. 22, 356 - St. Aeroporto, Mineiros - GO, 75833-130.

Como citar este artigo (Formato ABNT): ARAÚJO, Eleno Marques de; DUARTE, Emerson Mateus Souza. A filosofia da ciência: materialismo racional e formação do espírito científico na visão de Bachelard. Educação, Psicologia e Interfaces, v. 4, n. 1, p. 205-216, 2020. DOI: https://doi.org/10.37444/issn-2594-5343.v4i1.166

Recebido: 10/10/2019.

Aceito: 20/11/2019.

Educação, Psicologia e Interfaces, Volume 4, Número 1, p. 205-216, Janeiro/Março, 2020.

ISSN: 2594-5343. DOI: https://doi.org/10.37444/issn-2594-5343.v4i1.166 